\title{
Functional MRI and Response Inhibition in Children Exposed to Cocaine in utero
}

\author{
Preliminary Findings
}

\author{
Stephen J. Sheinkopf ${ }^{a} \quad$ Barry M. Lester $^{a}$ b Jerome N. Sanes ${ }^{c} \quad$ James C. Eliassen ${ }^{c}$ \\ Emmette R. Hutchison ${ }^{c}$ Ronald Seifer ${ }^{a}$ Linda L. LaGasse ${ }^{b}$ Sarah Durston ${ }^{d, e}$ \\ B.J. Casey ${ }^{d}$ \\ Departments of a Psychiatry and Human Behavior and bediatrics, Warren Alpert Medical School of Brown \\ University, ${ }^{C}$ Department of Neuroscience, Brown University, Providence, R.I., and ${ }^{\mathrm{d}}$ The Sackler Institute for \\ Developmental Psychobiology, Weill Medical College of Cornell University, New York, N.Y., USA; ${ }^{e}$ Department of \\ Child and Adolescent Psychiatry, The University Medical Center Utrecht, Utrecht, The Netherlands
}

\section{Key Words}

Prenatal cocaine $\cdot$ Neuroimaging $\cdot$ Cognitive

development $\cdot$ Inhibition

\begin{abstract}
This study investigated the potential long-term effects of cocaine exposure on brain functioning using $\mathrm{fMRI}$ in schoolaged children. The sample included 12 children with prenatal cocaine exposure and 12 non-exposed children (8-9 years old). Groups did not differ on IQ, socioeconomic status, or perinatal risk factors. A response inhibition task was administered during an $\mathrm{fMRI}$ scan using a 1.5-T MRI system. Task performance did not differentiate groups, but groups were differentiated by patterns of task-related brain activity. Cocaine-exposed children showed greater activation in the right inferior frontal cortex and caudate during response inhibition, whereas non-exposed children showed greater activations in temporal and occipital regions. These preliminary findings suggest that prenatal cocaine may affect the development of brain systems involved in the regulation of attention and response inhibition.
\end{abstract}

Copyright $\odot 2009$ S. Karger AG, Basel
(C) 2009 S. Karger AG, Basel

0378-5866/09/0312-0159\$26.00/0

Fax +4161306 1234

E-Mail karger@karger.ch

www.karger.com
Accessible online at:

www.karger.com/dne

\section{Introduction}

Prenatal exposure to cocaine may have long-term effects on brain development. Preclinical findings and theoretical models suggest that prenatal cocaine exposure will affect the long-term development of higher-order cognitive processes and related brain regions [1-3]. Longitudinal evidence indicates that there are long-term, though subtle, effects of prenatal exposure on behavior and cognitive functioning [4]. Direct evidence of longterm effects of prenatal cocaine exposure on brain development in children is emerging, but remains limited [5].

Using proton magnetic resonance spectroscopy, one study reported elevated creatine levels in frontal white matter in school-aged children with prenatal cocaine exposure [6]. Another study, using diffusion tensor imaging, found prenatal cocaine exposure to be associated with higher average diffusion in frontal brain regions in 10 year olds, including medial and lateral white matter tracts [7], suggesting immature development of frontal white matter tracts. One recent study reported reduced caudate volumes in adolescents with prenatal cocaine exposure [8], whereas another study of this same cohort reported increased resting cerebral blood flow in frontal 
and limbic regions [9]. These studies are consistent with earlier findings of short-term effects of prenatal cocaine on electrophysiologic measures of brain function, including lower EEG coherence at birth, lower spectral EEG power at 1 year of age [10], and prolonged brainstem conduction times, as measured by peak latencies on auditory brainstem response, at 1-month corrected age [11].

Findings from a recent fMRI study suggested that there was a subtle pattern of increased left prefrontal brain activation associated with increased working memory demands in cocaine-exposed adolescents versus nonsubstance-exposed controls [5]. No other studies have examined brain functioning in this population beyond early infancy $[10,11]$. Our study investigated the effects of prenatal cocaine exposure on brain functioning in a group of 8 to 9 -year-old children recruited from an ongoing longitudinal study of prenatal cocaine exposure, the Maternal Lifestyle Study (MLS). This subset of children from the MLS was examined in order to provide an initial test of hypothesized differences in brain functioning in children with prenatal cocaine exposure. Chronic cocaine use affects executive functions and related frontal brain regions in adults $[12,13]$. Animal models of prenatal cocaine exposure have documented effects on dopaminergic systems and frontal-striatal brain regions [14, 15]. Although research has not yet firmly documented effects of prenatal cocaine exposure on executive functions in humans, teratogenic models predict such effects $[2,3]$, and recent research has found increases in externalizing behaviors in cocaine-exposed children [16], which in turn is likely to be related to functional and structural differences in fronto-striatal brain regions $[17,18]$. Thus, based on this prior research, we predicted that functional differences for exposed children would be seen in regions including the prefrontal cortex, anterior cingulate, and related subcortical structures. We examined neural responses during a simple motor response inhibition task, chosen because such tasks test an aspect of executive control of cognition and behavior that has been consistently related to cocaine use in adults [19], and that may be related to the cognitive and behavioral risks seen in children with prenatal cocaine exposure.

\section{Methods}

\section{Participants}

Twenty-four right-handed 8 to 9 -year-old children were recruited from the Providence site of the MLS, an ongoing longitudinal study of the effects of prenatal cocaine exposure on child developmental outcome [20]. Prenatal exposure to cocaine was

Table 1. Subject characteristics

Prenatal cocaine
yes $(n=12) \quad$ no $(n=12)$

Sex

Male

Female

IQ score

Gestational age, weeks

Other prenatal drugs*

Alcohol

Tobacco

Marijuana

$\begin{array}{lc}5 & 7 \\ 7 & 5 \\ 89(77-111) & 88(70-105) \\ 37(29-41) & 38(33-42) \\ 12 & 7 \\ 7 & 6 \\ 9 & 5 \\ 3 & 0\end{array}$

Ranges are given in parentheses. The only significant difference between the groups was that cocaine-exposed children were more likely to have been exposed to other drugs. ${ }^{*} \mathrm{p}<0.05$.

identified by meconium toxicology (screen followed by gas chromatography/mass spectroscopy confirmation) and/or maternal self-report of use during pregnancy [21]. Exclusionary criteria included chromosomal abnormalities, TORCH (toxoplasmosis, rubella, cytomegalovirus, herpes, syphilis) infection confirmed before 1-month corrected age, or relocation outside the catchment area. A total of 1,388 children were included in the MLS (658 cocaine exposed and a matched sample of 730 unexposed), with 211 enrolled at the Providence site (107 cocaine exposed, 104 unexposed).

Informed consent was sought from a sequence of 33 of these eligible children and parents during study visits to the Providence MLS. Children with IQ scores $<70$ were not recruited for the fMRI study. Of the eligible children, 24 (73\%; 12 cocaine exposed and 12 non-exposed) completed the procedures (table 1). Children who completed the fMRI study were generally representative of the MLS sample. There were no significant differences between the fMRI and full MLS cohorts in terms of gender, socioeconomic status, birth weight, or gestational age. The fMRI sample was less likely than the full MLS sample to be described as black, although the fMRI sample was representative of the racial and ethnic characteristics of the Providence MLS cohort. Children in the fMRI sample had higher IQ scores than the overall MLS sample $(p=0.007)$, although this appeared to be a function of the recruitment criteria (there was no significant difference in IQ when limited to children with IQ $>70$ ).

Exposure to substances other than cocaine varied in both groups. Seven of the 12 children in the non-cocaine exposed group had prenatal exposure to alcohol and/or tobacco. Five children in the non-exposed group had no evidence of exposure to these substances. Eleven of the 12 children in the cocaine group were reported to have had prenatal exposure to alcohol, tobacco, or marijuana. The cocaine-exposed and non-exposed groups were balanced on gender, social class, gestational age (OB best estimate), and IQ (based on the Wechsler Intelligence Scale for Children III). The study was approved by the appropriate institutional review boards at the Women and Infants Hospital of Rhode 
Island, Memorial Hospital of Rhode Island, and Rhode Island Hospital. Informed consent was obtained from all parents or guardians, and all children provided assent.

\section{Experimental Design}

During the fMRI session, children were administered a variant of a go/nogo behavioral task based closely on the procedures previously reported $[18,22]$. The task utilized age-appropriate stimuli (Pokémon characters), and followed an event-related design [23]. Children were instructed to press a response button during most trials (go stimuli), and were instructed to withhold the response for 1 specific stimulus (the nogo stimulus). The task included 4 runs with 57 stimuli per run (including 43 go trials and 14 nogo trials). Order of presentation varied on a pseudorandom basis. Stimulus duration was $1,000 \mathrm{~ms}$ and interstimulus intervals varied on a pseudorandom basis between 3,000 and 5,000 ms (average interstimulus interval $=4,000 \mathrm{~ms}$ ). Task images were displayed onto a rear-projection screen placed at the foot of the MRI bed and were viewed via a mirror attached to the MRI head coil. Responses were recorded using an MR-compatible piano key response box placed on the right side of the participants. Children were instructed to press the button with their right index finger.

\section{Image Acquisition}

Images were acquired with a 1.5-T MRI system (Siemens Medical Solutions, Erlangen, Germany). Anatomic $\mathrm{T}_{1}$-weighted images were co-registered with functional echo planar $\mathrm{T}_{2}$-weighted images. Anatomic images were obtained using the following parameters: echo time $=4.1 \mathrm{~ms}$, repetition time $=1,900 \mathrm{~ms}$, field of view $=256 \mathrm{~mm}$, slice thickness $=1 \mathrm{~mm}$, resolution $=1 \times 1 \times$ $1 \mathrm{~mm}$.

Functional images were acquired with $\mathrm{T}_{2}$-weighted images using the blood oxygenation level dependent (BOLD) contrast [24]. Functional image acquisition utilized the following parameters: echo time $=38 \mathrm{~ms}$, repetition time $=3,840 \mathrm{~ms}$, field of view $=192$ $\mathrm{mm}$, slice thickness $=3 \mathrm{~mm}$, data matrix $=64 \times 64$, no skip, voxel size $=27 \mathrm{~mm}^{3}$. BOLD acquisitions were interleaved. Children were in the MRI scanner for 40-45 min, including two 7min structural scan sessions and functional imaging during the 4 runs of the event-related response inhibition task.

\section{Data Analysis}

The functional time series data were analyzed using the AFNI software [25]. Individual activation maps were created by fitting a $\gamma$-function model to the movement-corrected fMRI time series. BOLD signal change was modeled for correct responses (i.e. nogo trials where the child inhibited the button push). Images were normalized into a common stereotactic space [26] using standard coordinates [27], and data were pooled across participants within groups. Functional images were spatially blurred $(6 \mathrm{~mm}$; gaussian filter). Individual scans were averaged, and group functional activation maps were superimposed over a representative anatomic image.

\section{Statistical Analysis}

Subject data, including demographic information, prenatal drug exposure information, postnatal developmental data, and behavioral task performance results were analyzed with $\chi^{2}$ analyses for categorical data and t tests for continuous data. For fMRI data, voxel-wise tests of between-group differences in fMRI sig- nal change during nogo-correct trials were performed using ANOVA (i.e. differences between groups in the hemodynamic response during successful nogo inhibition trials). Results were thresholded using the 2-level correction for multiple comparisons ( $p<0.001$, clusters $>26$ voxels). Follow-up analyses were conducted within groups by testing for voxel clusters with significant fMRI signal change during nogo trials (i.e. BOLD signal during nogo trials minus average BOLD signal across the experiment). These tests utilized ANOVA and included the 2-level correction described above.

\section{Results}

\section{Subject Characteristics and Behavioral Data}

Cocaine-exposed and non-exposed children did not differ significantly in the percent of correct go trials or nogo trials. For go trials, the mean performance ( \pm SE) was $91 \pm 3 \%$ for exposed and $93 \pm 5 \%$ for non-exposed children. For nogo trials, the mean performance was 81 $\pm 3 \%$ for exposed and $76 \pm 5 \%$ for non-exposed children. One child in the non-exposed group had a low percentage of nogo-correct trials (48\%), and 1 child in the exposed group responded correctly on $61 \%$ of the nogo trials. Because these children had high response rates for go trials (<90\%), it was assumed that the correct responses to the nogo trials reflected successful inhibition of the motor response. Thus, their data were retained.

\section{Imaging Data}

Between-Group Effects

Statistically significant group differences in BOLD signal change were observed during nogo trials (table 2; fig. 1). Cocaine-exposed children showed greater BOLD signal change than non-exposed children in regions of the right inferior frontal cortex and the caudate body. In contrast, non-exposed children showed greater BOLD signal in regions of the left middle occipital cortex and the fusiform gyrus, among other regions.

\section{Within-Group Analyses}

We also conducted exploratory analyses in order to investigate the possible patterns of brain regions showing significant changes in BOLD signal associated with nogo correct trials within the cocaine-exposed and non-exposed groups. The cocaine-exposed group showed a pattern of activation that included the right hemisphere and anterior regions (table 3 ). For the cocaine exposed group, frontal activity was observed bilaterally in the anterior cingulate, as well as the right middle, superior, and medial frontal gyri. Other regions that showed activations 

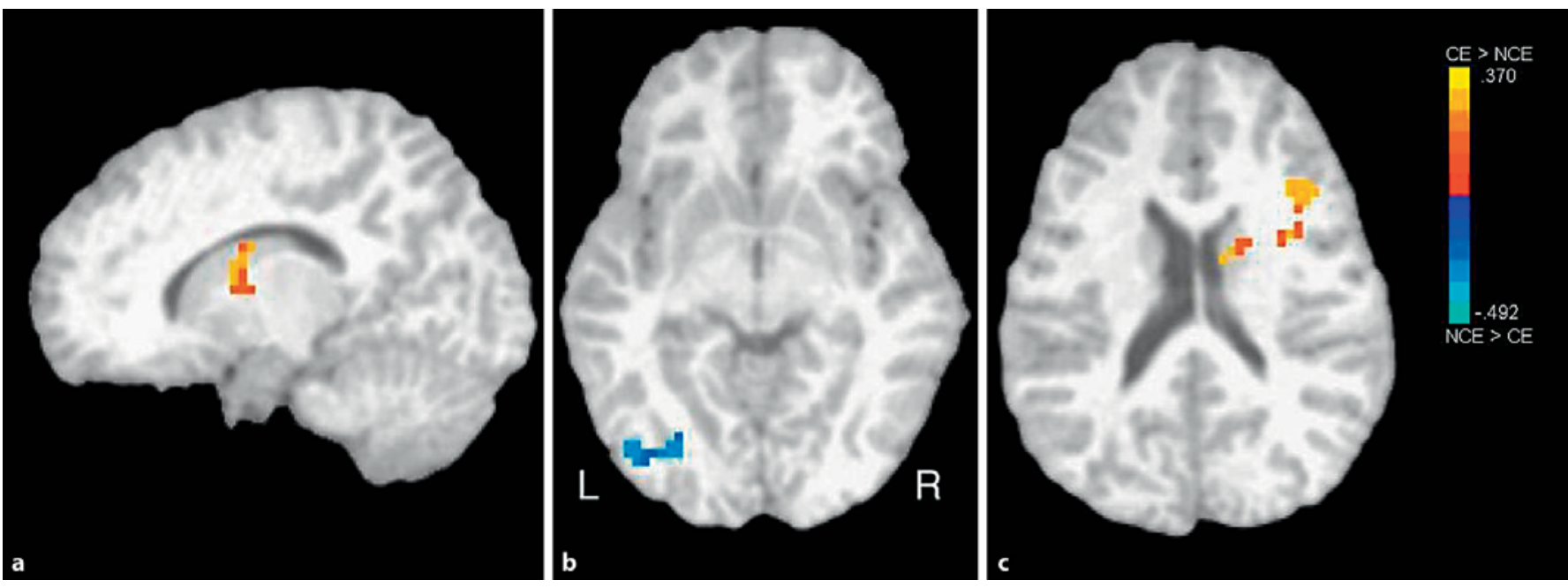

Fig. 1. Between-group effects: voxel clusters showing significant differences between groups in fMRI signal during nogo trials. a Right caudate: cocaine exposed (CE) > non-cocaine exposed (NCE). b Left occipital gyrus: NCE < CE. c Right frontal gyrus: CE > NCE.

Table 2. Regions with significant between-group differences in fMRI signal during nogo-correct trials (successful inhibitions)

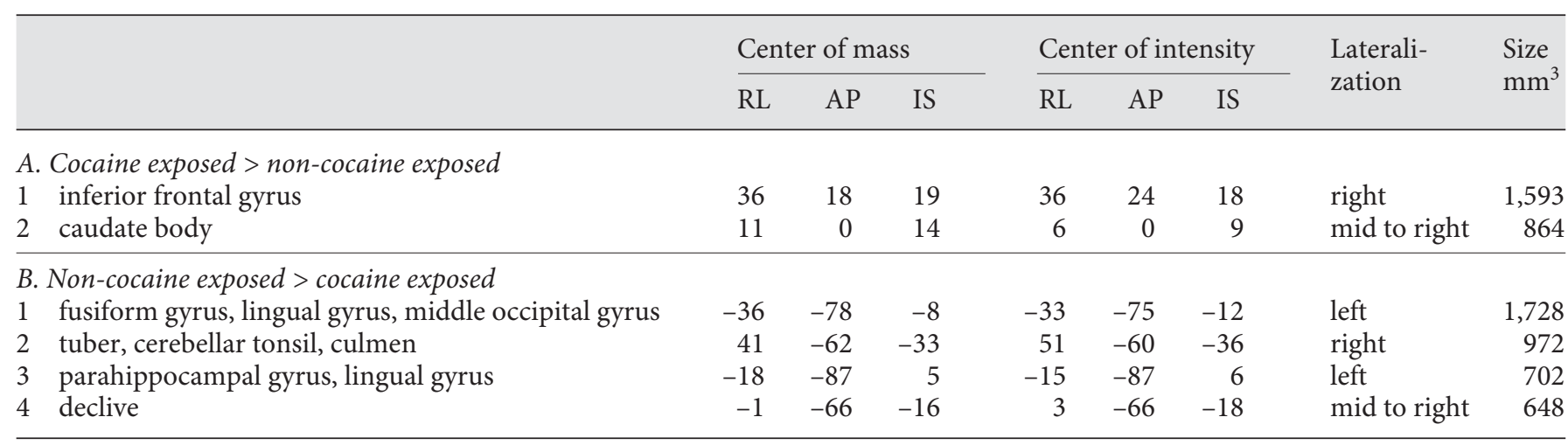

$\mathrm{RL}=$ Right-left; AP = anterior-posterior; IS = inferior-superior.

in this group were observed in the insula and in the striatum (right putamen and caudate body).

The non-exposed group showed a pattern of activation that was more posterior as compared to the exposed children, including bilateral activations in the fusiform gyrus, the inferior and middle occipital gyri, and the lingual gyri. Frontal regions that were activated in this group included left hemisphere regions of the superior, middle, and inferior frontal gyri. The non-exposed group also showed a small region of activation in the right anterior cingulate.

\section{Conclusion}

We investigated brain activation patterns in schoolaged children with prenatal cocaine exposure and nonexposed controls during a response inhibition task. The hemodynamic response to stimuli during response inhibition differed between exposed and non-exposed children. Cocaine-exposed children showed greater activation in frontal and striatal regions, areas that prior research has shown to be associated with controlled attentional processes in typically developing children [18]. In contrast, non-exposed children showed greater 
Table 3. Regions active during inhibition ('nogo') trials for cocaine-exposed (A) and non-exposed children (B)

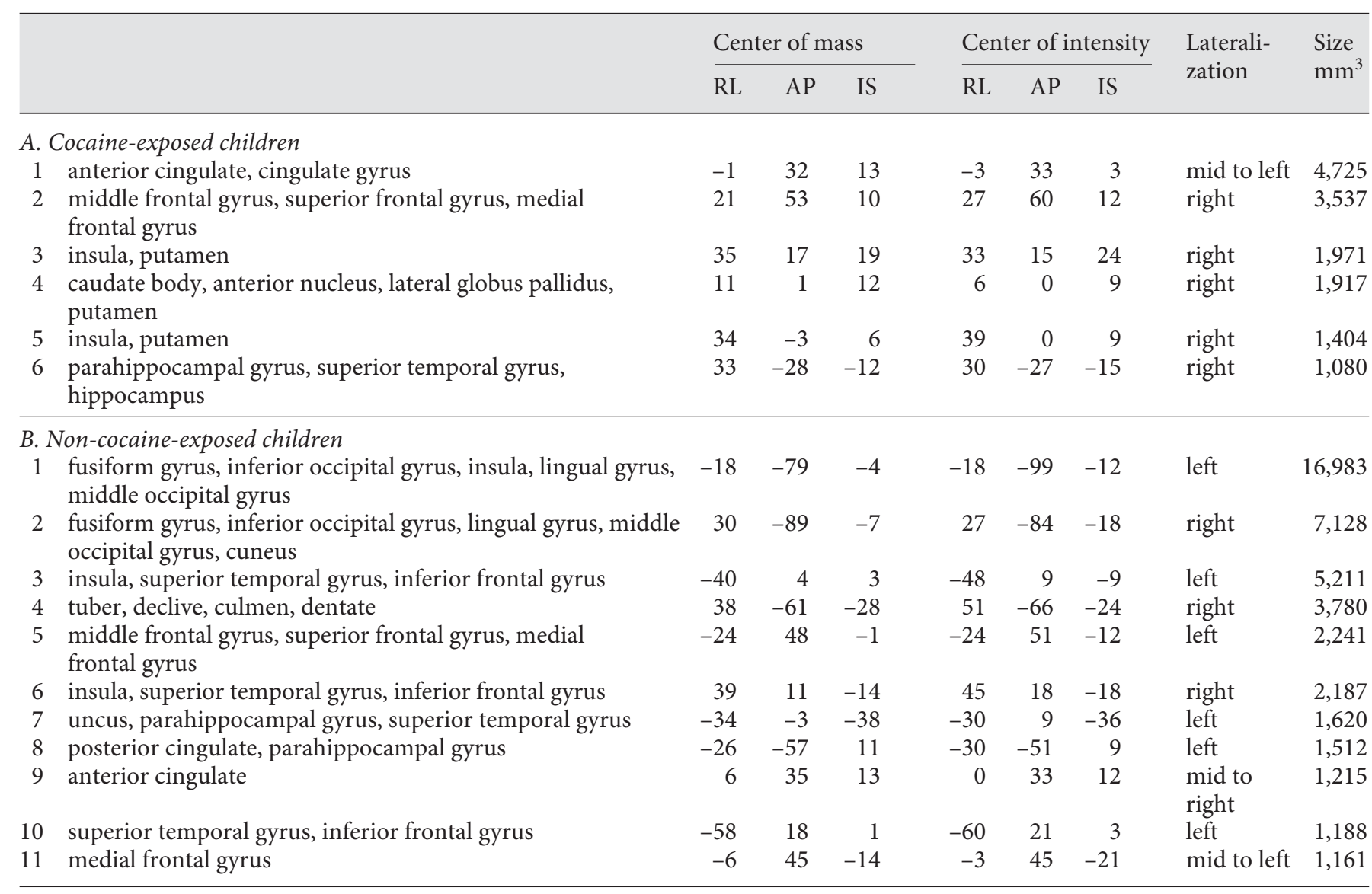

Clusters, with inclusive regions, in descending order by volume. RL = Right-left; AP = anterior-posterior; IS = inferior-superior.

activations in regions of the occipital cortex and the fusiform gyrus. The regions that were found to differentiate the cocaine-exposed from non-exposed children were generally similar to regions identified in prior research to be related to response inhibition in children and adolescents $[17,28]$. However, research has reported developmental changes across adolescence and into adulthood that reflect increased activation of frontal and striatal regions associated with response inhibition $[28,29]$. Developmental changes may reflect differential or alternative recruitment of brain regions to support cognitive functions with maturation $[28,30]$. While the current study was not longitudinal, these data do raise the hypothesis that prenatal cocaine exposure may affect long-term brain maturational processes underlying response inhibition.

These results are preliminary evidence that prenatal cocaine exposure is associated with functional differenc- es in neural systems underlying response inhibition. Exposed children appeared to recruit fronto-striatal networks during response inhibition to a greater extent than non-exposed children. Thus, one interpretation of these results is that prenatal exposure may affect brain regions that are involved in the cognitive control and regulation of attention. In this way, these results are consistent with the theory that prenatal cocaine exposure affects developing monoaminergic systems and executive functions $[1,2]$. This does not necessarily mean that our findings are reflective of functional deficits in fronto-striatal networks. As noted earlier, recent research has found that prenatal cocaine exposure may be related to elevated frontal creatine [6], elevated diffusion in frontal regions measured by diffusion tensor imaging [7], increased frontal cerebral blood flow [9], and increased left prefrontal activity measured by fMRI during a working-memory task [5]. Thus, one hypothesis going forward is that func- 
tional differences seen in this population may reflect the engagement of compensatory mechanisms during executive tasks. Other alternative explanations of these data are also possible. For example, the differences in the hemodynamic response in right frontal and striatal regions in the exposed group, as compared to occipital and temporal activations in the non-exposed group, could indicate more automatic processing of visual information in the non-exposed group, and thus may reflect a differential recruitment of brain regions rather than regional dysfunction, per se. Alternatively, groups may have differed in the degree of salience attributed to the task stimuli or to the degree to which they monitored their performance for errors.

These differences were not due to performance differences between the groups. Neuroimaging studies may be able to identify subtle but meaningful differences in cognitive processing even in the absence of performance differences on cognitive tasks. In fact, differences in brain function in the absence of performance deficits on a particular task or behavioral probe may have special value to the study of developmental psychopathology and the development of at-risk children [28].

These findings are also consistent with known longterm effects of cocaine in adults. Long-term effects of cocaine use on executive functions and measures of brain functioning in frontal regions subserving these functions, even after periods of abstinence, have been documented [12, 31]. Long-term cocaine use in adults is associated with reduced prefrontal cortical volume [13], decreased brain maturation in the frontal and temporal lobes [32], reduced white matter integrity in the frontal lobes [33], and decreased gray matter concentrations in orbitofrontal and anterior cingulate regions [34]. Although there is the possibility that our groups differed in patterns of functional activation in the anterior cingulate, these results were found in exploratory post hoc analyses, and thus cannot be considered definitive. Nonetheless, these results do raise the hypothesis that prenatal cocaine exposure may in some ways affect similar brain regions affected by chronic cocaine use in adults. Alternatively, these results raise the possibility that prenatal cocaine exposure may be associated with a differential recruitment of brain regions underlying cognitive inhibition.

Our results are also consistent with animal models, which predict some specificity of prenatal cocaine exposure effects on brain regions high in dopamine receptor concentrations $[14,35]$. However, the effects of prenatal cocaine are not limited to dopamine. For example, re- peated cocaine administration results in reduced GABAmediated inhibition of medial prefrontal neurons in adult rats [36]. Recent findings from a mouse model have demonstrated delayed tangential migration of GABA-ergic interneurons to cortical areas, including the medial prefrontal cortex, following prenatal cocaine exposure [37]. Thus, the effects of prenatal cocaine exposure on neurotransmitters are not limited to dopamine, and such effects (e.g. on the functional maturation of GABA circuitry) may contribute to some of our fMRI findings.

Past research has indicated that there may be reduced recruitment of brain regions associated with executive functions (e.g. working memory) as task performance becomes more automatic $[38,39]$. While the present study did not directly address this issue, it is possible that the groups differed in the degree to which they recruited more controlled attentional mechanisms to complete the nogo task. Thus, one hypothesis may be that prenatal cocaine impacts the integrity of brain regions that support the development of executive functions and that such effects may be reflected in subtle though functionally significant differences in cognitive, social, or adaptive functioning in this population.

There are limitations to this study. The sample size is small and most children were exposed to drugs other than cocaine. The design of the MLS allowed for exposure to alcohol, marijuana, and tobacco in the unexposed groups because it is well documented that most women who use cocaine also use these other substances. Cocaine-exposed children in the other imaging studies were also exposed to other substances $[5,6,9]$. The fact that we did find group differences with other substance exposure in both groups does point to the potential role of prenatal cocaine on the development of executive function-related brain systems. However, we could not fully explore the relative effects of cocaine and prenatal exposure to other substances. Also, the presence of other drug exposures in the comparison group allowed for a preliminary test of brain differences that may be more specifically attributable to cocaine exposure. However, the lack of a typical control group does not allow us to rule out the possibility that the children with other drug exposures were atypical in brain response as well.

Another potential limitation is that although we controlled for socioeconomic status, we cannot rule out other postnatal environmental factors that could have influenced our findings. We also cannot rule out the degree to which other child characteristics may have affected our findings. While the children in this study were representative of the overall MLS sample, it is possible that selec- 
tion biases (e.g. toward children who could complete the scan session; away from those children who declined to participate) may limit the generalizability of findings to the population of children with prenatal cocaine exposure. Related to this issue is whether the presence or absence of attention deficit hyperactivity disorder (ADHD) affected the findings. There were 5 children in this sample who later received diagnoses of $\mathrm{ADHD}$ at age 11 years, 3 in the cocaine exposed group and 2 in the non-cocaineexposed group (diagnosis determined by the Diagnostic Interview Schedule for Children) [40]. This sample composition did not allow for a full exploration of the effects of ADHD or other diagnostic classifications on the fMRI results, and this is recognized as a limitation to this study. However, the regional differences in brain activation between groups remain when these children with ADHD were excluded from the analyses on a post hoc basis. Finally, we did not exclude children based on history of prematurity for this preliminary study. Recent research has reported differences in brain structure and function in premature children, particularly in the temporal lobe
[41-43]. While the behavioral task employed in this study is different than those used in recent research with premature infants, it is acknowledged that this type of heterogeneity in our sample is a limitation. Thus, future work in this area should be designed to address these issues, either with statistical controls (requiring larger sample sizes) or more focused sampling and selection criteria.

The limitations identified above underscore the fact that these results need to be viewed as preliminary in nature. Nonetheless, if replicated, our findings would suggest that prenatal cocaine exposure is associated with long-term effects on brain development and could help explain the cognitive deficits that have been reported in this population, for example, in the area of executive function. It would also be important for future research to determine whether these deficits in brain function are related to other developmental outcomes such as school performance or psychopathology, including early onset of substance use in these children.

\section{References}

1 Volpe JJ: Effect of cocaine use on the fetus. New Engl J Med 1992;327:399-407.

-2 Mayes LC: A behavioral teratogenic model of the impact of prenatal cocaine exposure on arousal regulatory systems. Neurotoxicol Teratol 2002;24:385-395.

-3 Glatt SJ, Bolaños CA, Trksak GH, Jackson D: Effects of prenatal cocaine exposure on dopamine system development: a meta-analysis. Neurotoxicol Teratol 2000;22:617-629.

-4 Lester BM, LaGasse LL, Seifer R: Prenatal cocaine exposure and child outcome: the meaning of subtle effects. Science 1998;282: 633-634.

5 Hurt H, Giannetta JM, Korczykowski M, Hoang A, Tang KZ, Betancourt L, Brodsky NL, Shera DM, Farah MJ, Detre JA: Functional magnetic resonance imaging and working memory in adolescents with gestational cocaine exposure. J Pediatr 2008;152: 371-377.

6 Smith LM, Chang L, Yonekura ML, Gilbride K, Kuo J, Poland RE, Walot I, Ernst T: Brain proton magnetic resonance spectroscopy and imaging in children exposed to cocaine in utero. Pediatrics 2001;107:227-231.

7 Warner TD, Behnke M, Eyler FD, Padgett K, Leonard C, Hou W, Garvan CW, Schmalfuss IM, Blackband SJ: Diffusion tensor imaging of frontal white matter and executive functioning in cocaine-exposed children. Pediatrics 2006;118:2014-2024.
8 Avants BB, Hurt H, Giannetta JM, Epstein CL, Shera DM, Rao H, Wang J, Gee JC: Effects of heavy in utero cocaine exposure on adolescent caudate morphology. Pediatr Neurol 2007;37:275-279.

-9 Rao H, Wang J, Giannetta J, Korczykowski M, Shera D, Avants BB, Gee J, Detre JA, Hurt $\mathrm{H}$ : Altered resting cerebral blood flow in adolescents with in utero cocaine exposure revealed by perfusion functional MRI. Pediatrics 2007;120:e1245-e1254.

10 Scher MS, Richardson GA, Day NL: Effects of prenatal cocaine/crack and other drug exposure on electroencephalographic sleep studies at birth and one year. Pediatrics 2000;105:39-48.

-11 Lester BM, Lagasse L, Seifer R, Tronick EZ, Bauer CR, Shankaran S, Bada HS, Wright LL, Smeriglio VL, Liu J, Finnegan LP, Maza PL: The Maternal Lifestyle Study (MLS): effects of prenatal cocaine and/or opiate exposure on auditory brain response at one month. J Pediatr 2003;142:279-285.

12 Bolla KI, Rothman R, Cadet JL: Dose-related neurobehavioral effects of chronic cocaine use. J Neuropsychiatry Clin Neurosci 1999; 11:361-369.

13 Fein G, Di Sclafani V, Meyerhoff DJ: Prefrontal cortical volume reduction associated with frontal cortex function deficit in 6-week abstinent crack-cocaine dependent men. Drug Alcohol Depend 2002;68:87-93.
4 Levitt P: Prenatal effects of drugs of abuse on brain development. Drug Alcohol Depend 1998;51:109-125.

15 Murphy EH, Fischer I, Friedman E, Grayson D, Jones L, Levitt P, O’Brien-Jenkins A, Wang HY, Wang XH: Cocaine administration in pregnant rabbits alters cortical structure and function in their progeny in the absence of maternal seizures. Exp Brain Res 1997;114:433-441.

16 Bada HS, Das A, Bauer CR, Shankaran S, Lester B, LaGasse L, Hammond J, Wright LL, Higgins R: Impact of prenatal cocaine exposure on child behavior problems through school age. Pediatrics 2007;119:e348-e359.

17 Casey BJ, Castellanos FX, Giedd JN, Marsh WL, Hamburger SD, Schubert AB, Vauss YC, Vaituzis AC, Dickstein DP, Sarfatti SE, Rapoport JL: Implication of right frontostriatal circuitry in response inhibition and attention-deficit/hyperactivity disorder. J Am Acad Child Adolesc Psychiatry 1997;36:374383.

18 Durston S, Tottenham NT, Thomas KM, Davidson MC, Eigsti IM, Yang Y, Ulug AM, Casey BJ: Differential patterns of striatal activation in young children with and without ADHD. Biol Psychiatry 2003;53:871-878.

19 Bolla KI, Cadet JL, London ED: The neuropsychiatry of chronic cocaine abuse. J Neuropsychiatry Clin Neurosci 1998;10:280289. 
20 Lester BM, Tronick EZ, LaGasse L, Seifer R, Bauer CR, Shankaran S, Bada HS, Wright LL, Smeriglio VL, Lu J, Finnegan LP, Maza PL: The maternal lifestyle study: effects of substance exposure during pregnancy on neurodevelopmental outcome in 1-monthold infants. Pediatrics 2002;110:1182-1192.

-21 Lester BM, ElSohly M, Wright LL, Smeriglio VL, Verter J, Bauer CR, Shankaran S, Bada HS, Walls HH, Huestis MA, Finnegan LP, Maza PL: The Maternal Lifestyle Study: drug use by meconium toxicology and maternal self-report. Pediatrics 2001;107:309-317.

-22 Durston S, Thomas KM, Yang Y, Uluğ AM, Zimmerman RD, Casey BJ: A neural basis for development of inhibitory control. Dev Sci 2002;5:F9-F16.

-23 Dale AM, Buckner RL: Selective averaging of rapidly presented individual trials using fMRI. Hum Brain Mapp 1997;5:329-340.

-24 Kwong KK, Belliveau JW, Chesler DA, et al: Dynamic magnetic resonance imaging of human brain activity during primary sensory stimulation. Proc Natl Acad Sci USA 1992;89:5675-5679.

25 Cox RW: AFNI: software for the analysis and visualization of functional magnetic resonance neuroimages. Comput Biomed Res 1996;29:162-173.

26 Talairach J, Tournoux P: Co-planar Stereotaxic Atlas of the Human Brain. New York, Thieme, 1988.

-27 Mazziotta JC, Toga AW, Evans A, Fox P, Lancaster J: A probabilistic atlas of the human brain: theory and rationale for its development. The International Consortium for Brain Mapping (ICBM). Neuroimage 1995;2: 89-101.
8 Rubia K, Smith AB, Taylor E, Brammer M: Linear age-correlated functional development of right inferior fronto-striato-cerebellar networks during response inhibition and anterior cingulate during error-related processes. Hum Brain Mapp 2007;28:11631177.

29 Bunge SA, Dudukovic NM, Thomason ME, Vaidya CJ, Gabrieli JD: Immature frontal lobe contributions to cognitive control in children: evidence from fMRI. Neuron 2002; 33:301-311.

30 Tamm L, Menon V, Reiss AL: Maturation of brain function associated with response inhibition. J Am Acad Child Adolesc Psychiatry 2002;41:1231-1238.

31 Di Sclafani V, Tolou-Shams M, Price LJ, Fein G: Neuropsychological performance of individuals dependent on crack-cocaine, or crack-cocaine and alcohol, at 6 weeks and 6 months of abstinence. Drug Alcohol Depend 2002;66:161-171.

32 Bartzokis G, Beckson M, Lu PH, Edwards N, Bridge P, Mintz J: Brain maturation may be arrested in chronic cocaine addicts. Biol Psychiatry 2002;51:605-611.

33 Lim KO, Choi SJ, Pomara N, Wolkin A, Rotrosen JP: Reduced frontal white matter integrity in cocaine dependence: a controlled diffusion tensor imaging study. Biol Psychiatry 2002;51:890-895.

34 Franklin TR, Acton PD, Maldjian JA, Gray JD, Croft JR, Dackis CA, O’Brien CP, Childress AR: Decreased gray matter concentration in the insular, orbitofrontal, cingulate, and temporal cortices of cocaine patients. Biol Psychiatry 2002;51:134-142.

35 Reader TA, Masse P, de Champlain J: The intracortical distribution of norepinephrine, dopamine and serotonin in the cerebral cortex of the cat. Brain Res 1979;177:499-513.

36 Huang CC, Lin HJ, Hsu KS: Repeated cocaine administration promotes long-term potentiation induction in rat medial prefrontal cortex. Cereb Cortex 2007;17:18771888.
Crandall JE, Hackett HE, Tobet SA, Kosofsky BE, Bhide PG: Cocaine exposure decreases GABA neuron migration from the ganglionic eminence to the cerebral cortex in mice. Cereb Cortex 2004;14:665-675.

38 Jansma JM, Ramsey NF, Slagter HA, Kahn RS: Functional anatomical correlates of controlled and automatic processing. J Cogn Neurosci 2001;13:730-743.

39 Garavan H, Kelley D, Rosen A, Rao SM, Stein EA: Practice-related functional activation changes in a working memory task. Microsc Res Tech 2000;51:54-63.

40 Shaffer D, Schwab-Stone M, Fisher P, Cohen P, Piacentini J, Davies M, Conners CK, Regier D: The Diagnostic Interview Schedule for Children-Revised Version (DISC-R). I. Preparation, field testing, interrater reliability, and acceptability. J Am Acad Child Adoles Psychiatry 1993;32:643-650.

41 Kesler SR, Vohr B, Schneider KC, Katz KH Makuch RW, Reiss AL, Ment LR: Increased temporal lobe gyrification in preterm children. Neuropsychologia 2006;44:445-453.

42 Tolsa CB, Zimine S, Warfield SK, Freschi M, Sancho Rossignol A, Lazeyras F, Hanquinet S, Pfizenmaier M, Huppi PS: Early alteration of structural and functional brain development in premature infants born with intrauterine growth restriction. Pediatr Res 2004; 56:132-138.

43 Ment LR, Peterson BS, Vohr B, Allan W, Schneider KC, Lacadie C, Katz KH, Maller-Kesselman J, Pugh K, Duncan CC, Makuch RW, Constable RT: Cortical recruitment patterns in children born prematurely compared with control subjects during a passive listening functional magnetic resonance imaging task. J Pediatr 2006;149:490-498. 